\title{
SOBRE A POSSIBILIDADE DA MATERIALIZAÇÃO DO INCONSCIENTE
}

\author{
Daniel Francisco dos Santos
}

\begin{abstract}
RESUMO
O presente artigo tem por objetivo tratar da relação entre os escritos de Freud e Walter Benjamin a partir dos conceitos de inconsciente e de experiência, com o intento de vislumbrar a possível materialização do inconsciente. O vislumbre de tal possibilidade é permitido a partir da utilização que faz o filósofo alemão da teoria psicanalítica do trauma, ao forjar, em Charles Baudelaire: um lírico no auge do capitalismo, a teoria do declínio da experiência. Encontraremos em tal texto benjaminiano ao menos duas materializações do inconsciente, a primeira pensada a partir das mercadorias, objetos de culto nas passagens, e a segunda vinculada ao conceito proustiano de memória involuntária que elege, por sua vez, a madeleine como representante da materialização.
\end{abstract}

Palavras-chave: Benjamin. Freud. Experiência. Inconsciente

\section{ON THE POSSIBILITY OF MATERIALIZING THE UNCONSCIOUS}

\begin{abstract}
This article aims to address the relationship between the writings of Freud and Walter Benjamin from the concepts of unconscious and experience, with the intent to envision the possible materialization of the unconscious. The glimpse of such a possibility is allowed from the German philosopher's use of the psychoanalytic theory of trauma, by forging, in Charles Baudelaire: a lyrical at the height of capitalism, the theory of the decline of experience. We will find in such Benjamin text at least two materializations of the unconscious, the first thought from the goods, objects of worship in the passages, and the second linked to the Proustian concept of involuntary memory that elects, in turn, the madeleine as representative of materialization.
\end{abstract}

Key words: Benjamin. Freud. Experience. Unconscious. 
Na investigação dos escritos de Walter Benjamin e Freud, a partir dos conceitos de experiência e inconsciente em Charles Baudelaire: um lírico no auge do capitalismo, supomos que uma materialização ${ }^{1}$ do inconsciente toma forma. Tal suposição pode parecer, num primeiro momento, problemática, uma vez que pretende trazer um aspecto material a algo que não possui materialidade.

Para Freud, o inconsciente não possui status ontológico próprio, muito menos constituição anatômica específica. Com efeito, o inconsciente se apresenta erigido sob o plano simbólico. O máximo que se pode encontrar e que se aproxima da "materialização" do inconsciente é sua expressão como fenômeno. Nessa direção, tal fenômeno se apresenta aos olhos por meio da representação nos atos falhos, sintomas e sonhos, que fazem do inconsciente uma verdadeira realidade psíquica. Porém, é possível conceber uma materialização do inconsciente no pensamento de Walter Benjamin desenvolvido naquele texto de 1939.

A investigação a partir de tal texto benjaminiano nos levará a possibilidade de vislumbramos ao menos duas materializações do inconsciente. A primeira pensada a partir das passagens é representada pelas mercadorias, que são cultuadas como objetos de desejo e se traduzem pela expressão do inconsciente. Já a segunda é concebida a partir do conceito proustiano de memória involuntária, tendo a madeleine como expressão de tal materialização. Com efeito, veremos ambas as materializações brotarem no âmago da tese benjaminiana sobre a atrofia da experiência.

Para Walter Benjamin, tal atrofia se inicia, com a sobrecarga do aparelho sensorial do homem moderno. Nesse passo, a grande cidade, a multidão e o surgimento de novas técnicas sobrecarregam o citadino de Paris do século XIX de novas sensações, imprimindo um treinamento do aparelho sensorial. Esse treinamento exigiu adaptação ante a constante recepção dos estímulos. Sendo assim, um prejuízo à memória se estabeleceu e a experiência se viu reduzida.

Contudo, foi a partir da existência de um objeto como a madeleine que tal experiência pôde mais uma vez vislumbrar a possibilidade de vir à tona. Além do quê,

\footnotetext{
${ }^{2}$ A utilização da expressão materialização deve ser pensada longe de alguma analogia possível com o materialismo dialético ou histórico. A materialização no contexto do presente artigo deve ser entendida como externalização, projeção ou expressão do inconsciente nas coisas do mundo externo. Neste sentido, não indica propriamente uma materialidade do inconsciente, uma vez que seria improvável dentro das perspectivas teóricas aqui consideradas.
} 
diante da possibilidade de retorno da experiência foi possível observar que tal memória involuntária se traduz pelo conceito de inconsciente da psicanálise. Tal observação nos levou a perguntar quais mecanismos, visto da perspectiva também psicanalítica, melhor explicariam tanto o fenômeno do retorno da experiência quanto aquela possibilidade de materialização. Desse modo, supomos que tal processo pode ser vislumbrado de duas formas, a saber, pelas lembranças encobridoras e pelo processo de regressão nos sonhos.

Porém, veremos que tal possibilidade de retorno e materialização fracassarem, uma vez que, para Proust, o encontro com um objeto de tal tipo, que tivesse materializado o inconsciente, depende da contingência do acaso. Assim, escreve-nos Proust, podemos caminhar por toda nossa vida sem nunca nos depararmos com um objeto que ative em nós nosso passado como memória, logo, a experiência.

De semelhante modo, para Benjamin, em virtude do treinamento do sistema sensorial além da atrofia, tal encontro parece não ser mais possível. A experiência parece estar perdida. O que se pode encontrar é o demasiado crescimento das vivências. Contudo, por conta da vinculação do conceito de experiência ao inconsciente, supomos a possibilidade de prognóstico mais animador para a crescente condição de crescimento das vivências em detrimento da experiência.

Nesse sentido, veremos que a teoria dos atos falhos surge então como uma poderosa aliada em vista da provável recuperação da experiência, uma vez que, a partir de tal teoria, a experiência pode vislumbrar uma possibilidade real de acesso, além de uma viável materialização. De tal modo, o inconsciente pode se apresentar insertado nas coisas do mundo tais como as construções em ferro, as passagens, os reclames, no contexto de Paris do século XIX. O inconsciente passa a ser dado empiricamente, uma vez que se encontra na realidade externa, e não mais apresenta aquelas dificuldades que apontam as duas possibilidades de materialização.

Assim, com tal panorama em mente, o presente artigo tem por objetivo tratar da relação entre os conceitos de experiência e inconsciente, com o propósito de vislumbrar a possível materialização do inconsciente. Para tanto, baseamo-nos, além de nos escritos freudianos Interpretação dos sonhos, Além do princípio do prazer, Lembranças encobridoras e Sobre a psicopatologia da vida cotidiana, no texto de Walter Benjamin, Charles Baudelaire: um lírico no auge do capitalismo. 


\title{
1 Vivência e experiência: um treinamento do sistema sensorial
}

É em Charles Baudelaire: um lírico no auge do capitalismo, que Walter Benjamin trata do treinamento do sistema sensorial. As novas sensações da grande cidade, da Paris do século XIX, a multidão e o surgimento de novas técnicas sobrecarregavam o citadino moderno, imprimindo um treinamento para a recepção do grande volume de estímulos. Com ruas abarrotadas de pessoas, num intenso fluxo entre as massas, a grande cidade é o ambiente propício para o excesso de estímulos e situações de choque. Nesse ambiente, o indivíduo se encontra isolado, numa massa amorfa e normatizada que não representa nenhuma classe específica. A condição de isolamento é o preço que se paga pela busca do conforto. Nessa direção, em busca de melhores condições de vida, o homem encontrou, além daqueles benefícios, a proximidade com a mecanização (BENJAMIN, 1991, 125).

\begin{abstract}
Com a invenção do fósforo, em meados do século passado, surge uma série de inovações que têm uma coisa em comum: disparar uma série de processos complexos com um simples gesto. A evolução se produz em muitos setores; fica evidente entre outras coisas, no telefone, onde o movimento habitual da manivela do antigo aparelho cede lugar à retirada do fone do gancho. Entre inúmeros gestos de comutar, inserir, acionar etc., especialmente o "click" do fotógrafo trouxe consigo muitas consequências. Uma pressão do dedo bastava para fixar um acontecimento por tempo ilimitado. $O$ aparelho como que aplicava ao instante um choque póstumo. Paralelamente às experiências ópticas desta espécie, surgiam outras táteis, como as ocasionadas pela folha de anúncio dos jornais, e mesmo pela circulação na cidade grande (BENJAMIN, 2011, 124).
\end{abstract}

A proximidade com a mecanização pode ser entendida pela evolução tecnológica que se fez crescente "desde a invenção do fósforo", até se desenvolver ainda mais em diversos outros setores. A fotografia permitiu, a partir de um único "clique", o congelamento de um acontecimento em imagem, que proporcionava o deleite de quem a visualizasse. Não obstante, tal acontecimento, como tantos outros, podia se apresentar registrado por "tempo ilimitado". O telefone permitiu a atenuação do esforço que o antigo aparelho demandava com "o movimento habitual da manivela". Agora, para realizar a mesma operação, com o novo aparelho era preciso que apenas retirássemos o fone do gancho. É assim que tal economia de movimentos Doutorando em Filosofia pela Universidade Federal de Sergipe. Brasileiro, residente em Aracaju SE. E-mail: francisco.daniel58@hotmail.com 
traz a marca da simplificação de processos complexos em um movimento restrito. Além da grande quantidade de "anúncios de jornais" que incitam o manuseio num intenso folhear, de anúncio a anúncio, que proporciona estimulação tátil, também é observável como fenômeno da grande cidade os constantes esbarrões que o trânsito entre as massas proporciona aos sujeitos que se agregam naquelas situações de constantes estímulos e terminam por se obrigarem a uma adaptação do sistema sensorial (Ibid.).

Numa palavra, a técnica incita a um treinamento do aparelho sensório, uma vez que contribui para a grande quantidade de novas sensações. Portanto, a multidão e sua consequente pré-condição para o contato, a folha de jornal como novidade tátil e a fotografia como inovação visual consistem em exemplos de tais sensações que sobrecarregam o citadino moderno, fazendo da metrópole moderna um lugar marcado pela onipresença das situações de choque (lbid.).

O sistema sensório precisou, então, proteger-se da constante invasão de estímulos. Foi assim que a adaptação de tal sistema terminou por operar prejuízo à memória. Dito de outro modo, a grande incidência de estímulos ao sistema sensorial do homem moderno forçou, numa tentativa de proteção, a adaptação. Contudo, tal adaptação não se processou de maneira neutra, ou seja, sem prejuízos, uma vez que estes puderam ser sentidos na memória. Isso resulta em indivíduos mais ricos em vivências e mais pobres em experiência. Vivência e experiência se apresentam em polos distintos. Enquanto um corresponde à infeliz condição de proteção contra a constante invasão de estímulos, o outro, por sua vez, vê a memória atrofiar.

A imagem utilizada por Benjamin é a da esgrima. Numa luta de esgrima, o adversário profere uma sequência de vários golpes forçando seu oponente à defesa constante. Assim, o indivíduo que se defende das inúmeras estocadas da "espada" é comparável ao citadino que, na grande cidade, tem que, de semelhante modo, defender-se constantemente dos inúmeros estímulos. Com efeito, a memória e, logo, a experiência veem-se atrofiadas, uma vez que esta última é sacrificada no combate do sistema sensorial com os constantes choques (BENJAMIN, 2011, 111).

Para Benjamin, "[...] a experiência é matéria da tradição, tanto na vida privada quanto na vida coletiva. Forma-se menos com dados isolados e rigorosamente fixados na memória do que com dados acumulados, e com frequência inconscientes, que 
afluem à memória" (Ibid., 105). "A experiência é matéria da tradição" e seu teor é formado por elementos da "vida particular" e da "vida coletiva" dos indivíduos. São tais elementos que a condição de constante excitação da grande cidade impede de irromper. Aqueles estímulos que imprimiram um treinamento do aparelho sensorial, ou seja, as excitações táteis ou visuais ocasionadas pelas novas técnicas e pela crescente população, terminam por proporcionar um bloqueio a tais elementos. Estes são formados ao longo do tempo e se encontram sedimentados no "inconsciente". Nesse sentido, a experiência é formada por conteúdos da vida individual e coletiva dos sujeitos, e o inconsciente é onde ela faz residência.

Em outro momento, ainda em Charles Baudelaire: em lírico no auge do capitalismo, a experiência é então definida nos seguintes termos: "onde há experiência no sentido estrito do termo, entram em conjunção, na memória, certos conteúdos do passado individual com outros do passado coletivo. Os cultos, com seus cerimoniais, suas festas, [...] produziam reiteradamente a fusão desses dois elementos da memória" (Ibid., 107).

É na "experiência em sentido estrito do termo" que se pode encontrar tal fusão na memória dos elementos da tradição. Dos elementos do passado individual e coletivo os cultos e as festas repetidas vezes combinavam na memória, num passado de que parece não haver mais volta. Dizemos que tais conteúdos da experiência, os elementos da tradição apontam para a noção freudiana de fixação. É como se os elementos da experiência que se mantiveram na memória coletiva, por conta da fixação, se viram prejudicados pela onipresença das situações de choque.

E nessa direção, para acompanharmos o raciocínio benjaminiano no processo da atrofia da experiência, é preciso acompanhar o modo como utiliza, de maneira muito peculiar, a teoria freudiana do trauma.

Assim, é a partir da utilização do texto freudiano Além do princípio do prazer, que o processo de atrofia da memória, logo, da experiência, pode ser explicado. Em tal texto, a teoria do trauma servira de apoio no esclarecimento de sua tese sobre a atrofia da experiência. Nessa teoria freudiana, é possível observar que o movimento do aparelho psíquico é demasiadamente importante na dicotomia benjaminiana entre experiência e vivência. 


\section{A teoria freudiana do trauma}

Seguindo inicialmente Freud em Além do princípio do prazer, podemos observar que o psicanalista apresenta um importante passo na direção de sua complexa teoria do trauma. Ao investigar a maneira como os sentimentos de prazer e desprazer incidem em quantidade de excitação para o aparelho psíquico, observa-se que enquanto o aumento do prazer corresponde à diminuição de excitação, 0 desprazer corresponde à elevação dessa mesma excitação. Porém, tal relação não se resume a apenas uma contrapartida entre a intensidade de excitações, uma vez que a tendência de estabilidade também é considerada para manter a harmonia no aparelho mental. Assim, tal tarefa cabe ao princípio do prazer, considerado o responsável por manter as excitações no aparelho mental em quantidade reduzida ou de maneira constante (FREUD, 2006a, 19).

Porém, o princípio de prazer vê malograda sua função em duas diferentes ocasiões. Na primeira, influenciado pelos instintos de autopreservação do ego, aquele princípio é transmudado pelo princípio de realidade. Em outras palavras, em vista das exigências do mundo externo, o princípio do prazer precisa se adaptar, uma vez que ele se torna inoperante. Desse modo, é substituído pelo princípio de realidade, e sua demanda pelo constante prazer se vê diminuída (Ibid., 20).

$\mathrm{Na}$ segunda, o princípio do prazer encontra mais uma vez a liberação do desprazer diante dos conflitos internos inevitáveis na trajetória do desenvolvimento do ego, cabendo ao processo de repressão o afastamento de sua potencial satisfação. Com efeito, são tais fontes de desprazer que o aparelho psíquico inicialmente enfrenta (FREUD, 2006a, 20).

Porém, para Freud a maior parte do desprazer sentido pelo sujeito é decorrente do desprazer perceptivo. Por perceptivo não devemos entender apenas as excitações que são provenientes do mundo externo. Nessa direção, também são sentidas como estímulos perceptivos as pulsões internas insatisfeitas. São justamente aquelas 
primeiras que interessam a Walter Benjamin. Além da natureza de tais excitações, cabe agora também descrevermos a natureza do aparelho psíquico (Ibid., 21).

O aparelho psíquico é uma organização anímica que todos os homens possuem. Contudo, tal organização não possui status ontológico próprio, muito menos constituição anatômica específica, o que dificulta dizermos que a consciência é possuidora de uma natureza propriamente dita. Porém, tratando-se ou não de especulação, o psicanalista fala sobre a possibilidade de atribuir à consciência um lugar no espaço ao esboçar, com a imagem de um telescópio ou de uma máquina fotográfica, a imagem do aparelho psíquico como um instrumento formado por instâncias ou sistemas, a saber, o consciente, o pré-consciente e o inconsciente (FREUD, 2006b, 567).

Contudo, Garcia-Roza (2005), em seu livro Freud e o inconsciente, registra que a ideia de uma constituição anatômica do aparelho psíquico não passa de metáfora. Por mais que Freud, na Interpretação dos sonhos, faça analogias do aparelho psíquico com o aparelho ótico, como vimos agora a pouco, ou até mesmo com uma estrutura anatômica, tal "estrutura" não passa de metáfora, não possuindo, portanto, nenhuma constituição material (GARCIA-ROZA, 2005, 77).

Segundo Mezan, em Freud: a trama dos conceitos, as analogias freudianas que flertam com uma constituição ontológica são frutos da necessidade da época de buscar explicações para os processos mentais através de uma psicofisiologia. Nesse sentido, por mais que na obra freudiana tais analogias gerem confusões, uma diferença significativa é observada entre o contexto das obras Projeto para uma psicologia científica, de 1890, e Interpretação dos sonhos, de 1901. Enquanto no Projeto a referência aos processos mentais se concentra na constituição neurológica, com conjuntos de neurônios localizados no sistema nervoso, na obra de 1901, por sua vez, a relação entre o aparelho psíquico e suas excitações não indicam nenhum fundamento anatômico (MEZAN, 2008, 86).

Configurado numa hierarquia, o aparelho psíquico mantém relação de gradação entre suas instâncias, "[...] do mesmo modo que os vários sistemas de lentes de um telescópio se dispõem uns atrás dos outros" (FREUD, 2006b, 567). Cada uma das instâncias corresponde a uma função específica na dinâmica do aparelho psíquico, ao mesmo tempo em que possui uma localização espacial própria. Além do 
que, tais sistemas possuem direção peculiar e partem da recepção dos estímulos internos ou externos, até desembocar em uma inervação no sistema motor. Com efeito, o consciente aparece fixado como um órgão sensorial na recepção dos estímulos externos. Vale ressaltar que a consciência lida apenas com pequenas amostras do mundo externo, como tentáculos, diz-nos Freud, tateando os estímulos para logo em seguida recuar (FREUD, 2006a, 38). "As quantidades de excitação que provém do exterior possuem apenas um efeito reduzido" (Ibid., 39). Por sua vez, as excitações internas, uma vez que não encontram nenhuma barreira, apresentam-se mais intensas.

Contudo, dos estímulos que penetram a consciência não conservamos nenhum registro, nenhum traço sequer. Tal conservação, ou modificação permanente, traduzse pela memória propriamente dita. Portanto, para Freud a memória e os estímulos que adentram a consciência são incompatíveis. Numa palavra, onde há consciência não há memória (Ibid., 36).

A retenção de tais traços advindos da extremidade sensorial, ou seja, traços mnêmicos, fica a cargo de sistemas subsequentes. Por sua vez, o pré-consciente desenvolve uma "dupla" função no aparelho psíquico, uma vez que tramita servindo ao consciente e ao inconsciente. Enquanto os conteúdos deste último são inadmissíveis à consciência, o pré-consciente desenvolve a função de transportar tal conteúdo "proibido" por entre as instâncias incompatíveis. Em outros termos, o préconsciente assume papel intermediário, facilitando que conteúdos inconscientes cheguem até a consciência. Por fim, o inconsciente se estabelece como a última instância de tal organização anímica (FREUD, 2006b, 571).

São as lacunas em nossos dados da consciência que fazem Freud supor a existência do inconsciente. Tais lacunas, como exemplo, consistem de ideias, sintomas e sonhos, ou seja, atos psíquicos que de maneira geral irrompem em nossos processos mentais, advindos de lugar desconhecido. Quando procuramos um fio de explicação causal para tais atos, não sabemos por onde começar. Contudo, com a hipótese do inconsciente, esses atos psíquicos anteriormente inexplicáveis avistam possível deslindamento. $O$ inconsciente, a partir de então, passa a ser vislumbrado, uma vez que a partir de agora temos a porta que permite seu acesso (Ibid., 172). 
O inconsciente, registra Freud na Interpretação dos sonhos, não é erigido como um simples correlato, oposto à consciência. Este é a verdadeira realidade psíquica. À consciência, a partir de então, é atribuída papel secundário, concebida como um "órgão sensorial" voltada à percepção de qualidades psíquicas. Juntamente com o pré-consciente e o consciente, tais instâncias se configuram numa hierarquia do aparelho psíquico. Dito de outro modo, o aparelho psíquico concebido por Freud mantém uma relação de gradação entre suas instâncias. Nesse passo, o consciente aparece fixado como órgão sensorial para a recepção dos estímulos externos. O préconsciente, por sua vez, concebido como um inconsciente descritivo, assume o papel de intermediário entre o consciente e o inconsciente propriamente dito, uma vez que este é inadmissível à consciência. Nesse sentido, são estipulados dois inconscientes: um descritivo, que leva a rubrica de pré-consciente, e o outro dinâmico, denominado de inconsciente (FREUD, 2006b, 640).

Para Freud, é considerado trauma qualquer estímulo do mundo externo que implica perigo para a vida com força o bastante para romper aquele escudo protetor que envolve a consciência, tal processo se configura naquilo que denominou de neurose traumática. Em outras palavras, os estímulos que são provenientes da experiência da guerra, acidentes de trens, ou outros acidentes que envolvem perigo para a vida, são fortes o suficiente para romper o escudo protetor que envolve a consciência formando a neurose traumática. Quando tal barreira é rompida, a desorganização é instaurada no aparelho psíquico, forçando-o a se mobilizar em uma série de medidas defensivas, a fim de restabelecer o equilíbrio perdido (FREUD, 2006a, 40).

Tal evento traumático termina por congelar o momento exato em que o escudo protetor é rompido. O sujeito então passa a se encontrar "fixado" no instante do seu trauma, isto é, no momento do seu acidente. Por exemplo, Freud escreve que, em atividade onírica, o sono por vezes é interrompido por um susto, um susto diferente daquele primeiro da ocasião do acidente. Assim, o sujeito, ao dormir variadas vezes nos seus sonhos, vê-se transportado à exata situação que ocasionou o trauma, uma experiência assustadora. Como exemplo, ao sonhar, tal sujeito é remetido ao calor intenso, ao brilho ofuscante e ao ensurdecimento instantâneo, no momento em que a mina explode à sua frente, ou ao instante em que é arremessado do assento do trem 
quando este descarrilhou (Ibid., 23). Porém, quando desperto pelo susto que ocasionou tal sonho, o sujeito se dá conta de que se encontra em situação mais confortável.

Contudo, tal condição traumática não se restringe apenas às situações em que o ferimento físico é infligido. Freud observa que mesmo aqueles homens que não se encontravam na linha de frente de batalha ${ }^{2}$ também apresentavam semelhante condição de sofrimento, do mesmo modo que "pessoas normais", ou seja, não combatentes que em sua rotina ordinária em tempos de paz também desenvolviam algum tipo de sofrimento similar (FREUD, 2006e).

Entretanto, mais uma vez em seu texto, uma observação é realizada acerca da natureza do trauma. Era preciso também distinguir a natureza do trauma da "neurose clínica" - ou neuroses espontâneas, como chamou Freud - das neuroses traumáticas. "As neuroses traumáticas não são em essência semelhantes às neuroses espontâneas" (Ibid., 282), isto é, neuroses tratadas na prática clínica. No entanto, ambas as neuroses possuem um ponto em comum, uma vez que ambas as afecções apontam para um momento traumático desencadeante. Em outros termos, a neurose espontânea difere da neurose traumática por remeter o indivíduo ao momento de sofrimento em instantes distintos. Enquanto na neurose traumática, isto é, a neurose ocasionada por sofrimento físico, a fixação no trauma se dá no instante do acidente, a neurose espontânea não respeita a precisão do acontecimento, podendo remeter a qualquer momento da história do indivíduo (FREUD, 2006e).

Além do mais, outra questão de extrema relevância é apontada neste mesmo ensaio. Se, para Freud, o sonho é a realização de desejo, parece curiosa a recorrência do instante traumático nos sonhos, uma vez que o sujeito não desejaria ser levado nos seus sonhos repetidas vezes àquele momento doloroso (FREUD, 2006a, 42). que significa a fixação do trauma nos sonhos? Porém, em Além do princípio do prazer,

\footnotetext{
${ }^{2}$ Ernest Jones, biógrafo e amigo de Freud, observa o quanto foi importante a leitura freudiana a respeito do trauma nas referidas neuroses de guerra. Antes da convocação de Freud para compor uma junta médica especial com o intuito de examinar os combatentes que retornavam do front, os neuróticos de guerra eram submetidos aos métodos mais cruéis de tratamento. Tais métodos consistiam na aplicação de fortes correntes elétricas a fim de extirpar a fonte do sofrimento dos pacientes. Porém, o tratamento à base de correntes elétricas, por mais que conseguisse um sucesso inicial e o paciente fosse considerado curado, em seguida recaia enfermo, sendo necessárias novas sessões de tratamento (JONES, 1970, 587).
} 
ele abdica de levar mais adiante tal questionamento, passando a tratar da repetição das brincadeiras infantis. A apresentação do desenvolvimento freudiano sobre a neurose traumática cumpre aqui o papel de breve comparativo entre as diferentes concepções de "excitação traumática" para ambos os pensadores. Assim, uma vez apresentada as principais premissas da teoria freudiana do trauma, cabe agora voltarmos para a questão de como se dá o processo de atrofia da memória à luz do conceito benjaminiano de experiência.

Recapitulando, vimos que é diante do quadro da onipresença das situações de choque, esboçado anteriormente, que Walter Benjamin pega de empréstimo a psicodinâmica do aparelho psíquico encontrada na teoria do trauma da psicanálise. Assim, na grande metrópole o indivíduo é exposto a uma grande variedade de estímulos que assomam no exterior e invadem seu mundo interno, ou seja, seu aparelho psíquico. Porém, não se trata de uma mera invasão sem encontrar nenhuma resistência. É aqui que o treinamento do sistema sensorial é posto à prova. No combate a tal invasão, a consciência com seu escudo protetor é a responsável por amparar tais estímulos. Com a rubrica de choques, vimos que aqueles estímulos ocasionam prejuízo à memória. Esse processo ocorre porque quanto mais a consciência é acionada na atenuação da grande quantidade de estímulos do mundo externo, mais a memória se vê prejudicada em sua retenção. $O$ choque que é assim aparado faz daquele estímulo do qual a consciência se defendeu uma "experiência vivida em sentido restrito" (BENJAMIN, 2011, 110).

Dito de outro modo, o trabalho da consciência em defender o mundo interno dos constantes estímulos do mundo externo resulta no crescimento das vivências. Tal crescimento das vivências implica empobrecimento da experiência. Portanto, enquanto a vivência se encontra associada ao trabalho do escudo protetor da consciência, a experiência, por sua vez, aparece vinculada à memória, logo, ao inconsciente. Com isso, Benjamin exclui desse processo todo o trabalho da reflexão. Nessa direção, como exemplo, todo o esforço de evocar da memória uma lembrança qualquer não satisfaz como um conteúdo daquela experiência. Numa palavra, os conteúdos da experiência não afluem à memória por um ato de volição consciente. Tais lembranças são inconscientes em si mesmas (Ibid., 106). 
Porém, Walter Benjamin não confere lugar específico diferente da memória para a demanda de estímulos que excede o escudo da consciência. Em outros termos, se o êxito da consciência em aparar os choques for medíocre, mais estímulos invasores serão incorporados à experiência e, muito provavelmente, ao inconsciente. Mas não só. Benjamin também chama a atenção para os elementos inconscientes que pertencem à categoria da experiência e que são matéria da tradição. Com efeito, é possível dizer que a experiência habita o inconsciente. E veremos que tal parte do inconsciente é composta por dois elementos.

\section{O conteúdo da experiência}

Vimos anteriormente que a experiência, em sentido estrito do termo, funde na memória o conteúdo do passado individual e do passado coletivo. Tal conceito de experiência faz contraposição àquela experiência em sentido restrito, ou seja, à experiência atrofiada resultante do treinamento ${ }^{3}$ do aparelho sensorial.

Dispensada a atividade consciente do âmbito da experiência, esta é composta por ao menos dois elementos, a saber, pelos dados isolados que se fixaram na memória e pelos dados inconscientes conservados ao longo dos anos.

Para Benjamin, as excitações externas que produzem efeito traumático são incorporadas à experiência. Desse modo, se o que caracteriza a grande cidade é a onipresença das situações de choque, ou seja, onipresença das vivências em detrimento da experiência, isso nos leva a deduzir que o efeito traumático do choque também é reduzido. Diz-nos Benjamin $(2011,109)$ : “Quanto mais corrente se tornar o registro desses choques no consciente, tanto menos se deverá esperar deles um efeito traumático". Com efeito, podemos concluir que nem todo choque é traumático, uma vez que, se voltarmos a Freud, veremos que quanto maior for o trabalho da

\footnotetext{
${ }^{3}$ Porém, se seguirmos o raciocínio benjaminiano em outros textos como Experiência e pobreza e o Narrador, podemos observar que o fenômeno da redução da experiência se dá também em virtude de outros fatores diferentes do treinamento do aparelho sensorial. Assim, aspectos históricos e sociais, como a experiência da guerra e a morte da narrativa, também contribuem para a diminuição da experiência autêntica.
} 
consciência em proteger o aparelho psíquico contra a invasão dos estímulos, menor será o seu registro no âmbito da memória (Ibid., 111).

Contudo, Rouanet em Édipo e o anjo, escreve que a leitura benjaminiana da teoria freudiana do trauma é equivocada, uma vez que Benjamin termina por considerar como choque qualquer estímulo advindo do mundo externo. O equívoco de Benjamin, diz o comentador, consistiu em não considerar que, em Freud, somente as excitações traumáticas são geradoras de choque, assim, nem todo acontecimento é trauma ou choque (ROUANET, 1981, 74).

Porém, já em Freud, registra Kehl em O tempo e o cão, choque e trauma são coisas distintas. $O$ choque na perspectiva freudiana equivale à mera recepção do estímulo. O estímulo responsável por um efeito traumático seria o estímulo forte o suficiente para romper o escudo protetor que envolve a consciência (KEHL, 2014, 174). Nesse sentido, o que interessa a Benjamin na relação choque e trauma é a rapidez com que a consciência é invadida pelo prosaico e pelos constantes choques, e não propriamente o evento fixado num trauma (lbid., 175).

Feitas as devidas ponderações, dizemos que com essas pistas é possível pensar que tais excitações externas, que produzem um efeito traumático nos sujeitos e são incorporadas à experiência, interessam em demasia a Walter Benjamin, configurando-se como o primeiro elemento. Como hipótese, dizemos que tal elemento da experiência é nutrido pelo conteúdo do passado individual dos sujeitos. Nesse sentido, podemos imaginar o dia a dia dos citadinos de Paris como o grande palco para tais elementos da experiência. Por aqueles dados isolados que se fixaram na memória, supõe-se a referência aos estímulos que não foram interceptados pelo escudo protetor da consciência. Numa palavra, um choque não aparado pela consciência passa à memória como trauma.

Como dito anteriormente, a concepção benjaminiana de trauma pode ser entendida junto à concepção psicanalítica de neurose traumática. Dito isso, não queremos negar que a concepção do filósofo alemão de trauma the seja peculiar e que seja distinta da concepção freudiana de trauma. É sabido que, vinculada ao conceito de experiência, pode-se observar que tal concepção psicanalítica é absorvida e expelida de modo distinto. 
Para Freud, o trauma corresponde às excitações externas, tais como "[...] graves concussões mecânicas, desastres ferroviários e outros acidentes que envolvem 0 risco de vida [...]" (FREUD, 2006a, 23). Assim, um desastre ou um ferimento ocasionado por acidente demandam excitação demasiadamente forte para romper o escudo protetor que envolve a consciência, produzindo efeito traumático. Contudo, em Walter Benjamin, uma explicação de tal tipo não se faz presente. Só sabemos que, de modo semelhante a Freud, considera como potencialmente traumáticas excitações advindas do exterior, mas difere ao não considerar o efeito das excitações internas ao aparelho psíquico. Como Benjamin não especifica quais tipos de excitações externas podem ou não desenvolver um efeito traumático, abre caminho para pensar quais estímulos se prestam àquele fim. Portanto, o trauma, logo, a experiência, encontra-se vinculado ao passado individual, às situações isoladas que o transitar rotineiro pelas ruas da grande cidade pode por vezes acometer os sujeitos.

O segundo elemento da experiência abrange sua maior parte. Diferentemente daqueles dados isolados que compõem o primeiro elemento, os dados aqui inconscientes são acumulados ao longo do tempo, podendo afluir à memória. Enquanto que os dados isolados recolhidos das excitações externas correspondem a elementos do passado individual dos sujeitos, pode-se supor que tais dados inconscientes têm por seu conteúdo elementos do passado coletivo da espécie. Assim, tanto os elementos que compõem o primeiro elemento da experiência e que irrompem no contexto da grande cidade quanto os elementos que formam o segundo elemento da experiência e que foram conservados ao longo dos anos são dependentes da noção freudiana de fixação. Nesse sentido, ambas os elementos dependem, ou uma vez dependeram, da influência do contexto histórico nos processos inconscientes dos sujeitos.

"A experiência que é matéria da tradição, tanto na vida privada quanto na coletiva" (BENJAMIN, 2011, 105), diante de um dos fenômenos da Modernidade, isto é, ante a onipresença das situações de choque, vê-se ofuscada ante o despontar da vivência. E aqui dizemos que os "dados que são acumulados e que com frequência são inconscientes" (Ibid., 105) extrapolam o foco de sua utilização para além da teoria freudiana do trauma. Dito de outro modo, Benjamin, ao tratar da antinomia vivência e experiência, apesar de se filiar à teoria freudiana do trauma na operação do conceito 
de choque, não fundamenta sua tese do prejuízo da experiência apenas nesse aspecto. Como hipótese, dizemos que o interesse de Walter Benjamin se concentra no movimento das impressões pelas instâncias, tendo em vista o local que a experiência habita e um possível movimento retrocedente, que se pode vislumbrar na possibilidade de recuperação.

Com a possibilidade de os dados inconscientes afluírem à memória, como mostra Benjamin na citação, dizemos que fica aberta também possibilidade de recuperação da experiência. Se o quadro de atrofia dessa última fosse de todo ruim, tal possibilidade não existiria, e nem seria posta como alternativa. Porém, com aqueles fenômenos da modernidade que implicaram treinamento do aparelho sensorial, tal alternativa, num primeiro momento, vê-se fracassada. Entretanto, se acompanharmos as pistas, uma via de restauração da experiência pode ser pensada. Nessa direção, a existência de um objeto material se prestaria a tal fim. Dito de outro modo, a experiência pode retornar ao indivíduo se ele, em sua trajetória, encontra um objeto que lhe desperte tal memória adormecida. Com efeito, dizemos que tal via de restauração se processa como a possibilidade de materialização do inconsciente em um objeto de tal tipo.

\section{As possíveis materializações do inconsciente}

Como pensar em algo como a materialização do inconsciente, se este não possui status ontológico próprio, muito menos constituição física específica?

Vimos anteriormente que o inconsciente constitui uma verdadeira realidade psíquica por conta dos seus remanescentes, a saber, os sonhos, os sintomas e os atos falhos. Porém, o inconsciente não é provido de nenhuma materialidade. Em Freud, o máximo que podemos encontrar e que se aproxima de uma "materialização" é a expressão do inconsciente como fenômeno. Portanto, o inconsciente se apresenta por meio dos atos falhos, sintomas e sonhos.

Contudo, apesar de tais fenômenos serem detectáveis, isso não implica necessariamente a materialização daquilo que é sua fonte, ou seja, daquilo que é força de sua expressão. Em outros termos, por mais que o inconsciente se expresse 
nas mais diversas formas, não traz precisamente a garantia de uma constituição física ou material para a psicanálise, e sim indício de realidade psíquica, como aponta Freud.

Porém, em Walter Benjamin tal assertiva pode ser considerada de outra forma, e a materialização do inconsciente pensada aqui de dois diferentes modos, a saber, com a condição de fetiche da mercadoria e a partir do conceito proustiano de memória involuntária.

A primeira materialização pode ser pensada a partir das passagens. Centros de mercadorias de luxo, as passagens ou galerias surgem em Paris a partir de 1822. Em tais espaços, as mercadorias eram cultuadas como objetos de desejo por aqueles que as avistavam expostas nas vitrines. Idealizado o valor de troca dessas mercadorias, o valor de uso se apresenta diminuído. As passagens abrigam, desse modo, mercadorias e consumidores em potencial. Com efeito, tais mercadorias nas galerias se traduzem por expressão de desejo, inconsciente, daqueles que por ela transitam (BENJAMIN, 2006).

Em outras palavras, as mercadorias como objetos de desejo, expostas em vitrines podem ser vistas como exemplo da materialização do inconsciente, uma vez que este implica o desejo. A mercadoria então passa a ser expressão coisificada de tal desejo do inconsciente, bastando, para que se realize, a sua compra. Mas aqui cabe questionar se é mesmo possível atestar tal materialidade do inconsciente pela compra de um produto qualquer. Se assim for, um casaco de pele ou um relógio, por exemplo, dão de fato mostra de uma constituição física do inconsciente? Ou Benjamin nos fala sobre algo mais?

Pensada sob tal ótica, essa materialização não consiste em elementos inconscientes nas coisas do mundo, uma vez que se reduz ao desejo vazio de um único sujeito. Dito de outro modo, ao tratarmos da materialização do inconsciente, não nos referimos propriamente à matéria de determinados objetos, ou a objetos que foram confeccionados por um artesão qualquer, ou a monumentos que foram projetados por um artista ou arquiteto, que nos leva a dizer que são imagens de um único inconsciente materializado.

Mas a materialização do inconsciente sob a ótica daquelas duas perspectivas se dá do sujeito coletivo para as coisas do mundo. É na relação sujeito e mundo que o inconsciente pode materializar-se. Pensada daquela forma, a materialização se 
restringiria àquele que dela deriva, isto é, ao inconsciente particular, no ponto em que este só abrange conteúdos do passado recente, sem a perspectiva do conteúdo coletivo, não se tratando de uma materialização, mas de várias materializações do inconsciente, uma vez que se trata de vários sujeitos. Entretanto, o que ajuda a responder esse impasse é a tentativa de conceber tal inconsciente como residência daquela experiência em sentido estrito, isto é, como experiência que agregue na memória conteúdos do passado individual e do passado coletivo dos sujeitos. Nesse passo, o desejo que as mercadorias despertam nos indivíduos são desejos esvaziados de experiência, em sentido estrito. É como o desejo do jogador ou o movimento repetitivo do operário diante da máquina (BENJAMIN, 2011, 129).

Para Benjamin, a dinâmica do jogo também trata de desejo, porém, de um falso desejo. A vontade de ganhar e de ficar rico no jogo não implica desejo, no verdadeiro sentido do termo. Pertencente à categoria da experiência, um desejo autêntico, quando realizado, termina por coroar a experiência (Ibid., 129).

Se a vivência do choque na grande cidade equivale à repetição dos movimentos do operário numa máquina e do mesmo modo desenvolve dinâmica parecida com o desejo esvaziado dos jogos de azar, também podemos dizer que o torpor que o fetiche da mercadoria suscita nos passantes das galerias não passa de falsos desejos, uma vez que, para Walter Benjamin, um desejo, no verdadeiro sentido do termo, pertence à categoria da experiência. Assim, a normatização da vida dos sujeitos na grande cidade os levou a serem desejosos dos mesmos elementos, a saber, as mercadorias das passagens. Numa palavra, os indivíduos normatizados e os desejos em comum resultam também em normatização do desejo. Com efeito, a normatização da vida implica também normatização do desejo (Ibid., 127).

A segunda materialização pode ser pensada a partir do conceito proustiano de memória involuntária. Diferente da primeira, tal materialização corresponde como elemento da experiência em sentido estrito. Walter Benjamin, citando Marcel Proust, faz referência à possível existência de um objeto que pode nos remeter ao passado, que pode nos dar acesso à experiência. Sendo assim, citamos um trecho da obra de Proust Em busca do tempo perdido (2014).

Fazia já muitos anos que, de Combray, tudo que não fosse o teatro e o drama do meu deitar não existia mais para mim, quando num dia de inverno, 
chegando eu em casa, minha mãe, vendo-me com frio, propôs que tomasse, contra meus hábitos, um pouco de chá. A princípio recusei e, nem sei bem por quê, acabei aceitando. Ela então mandou buscar um desses biscoitos curtos e rechonchudos chamados madeleines que parecem ter sido moldados na valva estriada de uma concha de São Tiago. E logo, maquinalmente, acabrunhado pelo dia tristonho e à perspectiva de um dia seguinte igualmente sombrio, levei à boca uma colherada de chá onde deixara amolecer um pedaço da madeleine. Mas no mesmo instante em que esse gole, misturado com os farelos do biscoito, tocou meu paladar, estremeci, atento ao que se passava de extraordinário em mim. Invadira-me um prazer delicioso, isolado, sem a noção de sua causa. Rapidamente se me tornaram indiferentes às vicissitudes de minha vida, inofensivos os seus desastres, ilusória sua brevidade, da mesma forma que opera o amor, enchendo-me de uma essência preciosa (PROUST, 2014, 71).

[...] E de súbito a lembrança me apareceu. Aquele gosto era o do pedacinho da madeleine que minha tia Léonie me dava aos domingos pela manhã em Combray (porque nesse dia eu não saía antes da hora da missa), quando ia Ihe dar bom-dia no seu quarto, depois de mergulhá-lo em sua infusão de chá ou de tília. A vista do pequeno biscoito não me recordara coisa alguma antes que o tivesse provado; talvez porque, tendo-o visto desde então, sem comer, nas prateleiras das confeitarias, sua imagem havia deixado aqueles dias de Combray para se ligar a outros mais recentes; talvez porque, dessas lembranças abandonadas há tanto tempo fora da memória, nada sobrevivesse, tudo se houvesse desagregado (Ibid., 73).

Podemos observar, com a citação, o efeito que tal objeto que traz em si materializada a experiência pode suscitar no sujeito. O contato com a madeleine reenvia o indivíduo para o seu passado, uma vez que a memória irrompe subitamente. O contato com a madeleine proporciona, de forma instantânea, uma explosão de sensações, um reverso em seu ânimo, a felicidade de poder contar mais uma vez com aquele passado antes esquecido. Contudo, tal remissão do passado não pode ser controlada. Não é apenas o encontro com a madeleine que despertou o indivíduo para o seu passado. Dito de outro modo, "a vista do pequeno biscoito não me recordara coisa alguma antes que o tivesse provado". Nesse sentido, o que fez retomar parte daquela memória perdida foi o conjunto de pequenas situações que se desenrolaram na casa onde residiu em sua infância. Sendo assim, não só o contato visual com o biscoito, mas seu sabor misturado com o chá ajudou o indivíduo a lembrar das manhãs de domingo em Combray, com sua tia Léonie.

Tal remissão ao passado depende do acaso, uma vez que não se sabe qual objeto pode produzir tal efeito, muito menos o exato momento do seu encontro, e que constelação de circunstâncias será necessária para tal. O conteúdo que é assim acionado corresponde ao conceito proustiano de memória involuntária. Nessa esteira, 
é vedada a esta última a tentativa de evocação de maneira voluntária, isto é, consciente, logo, a reflexão é excluída do processo. Como exemplo, o simples fato de olhar para o biscoito não proporcionou nada de novo, ou melhor, nada do passado, justaposto àquela imagem do biscoito (Ibid., 73).

Dito de outro modo, a possibilidade de um objeto disparar, naquele que o encontra, a memória que concerne ao seu passado exclui a tentativa de evocação voluntária de tal conteúdo esquecido. Sendo assim, o máximo que o sujeito pode conseguir é a evocação de uma lembrança que não traz o passado em sua inteireza.

Para Benjamin, a memória involuntária equivale à memória na acepção psicanalítica. Nessa direção, podemos dizer que o conceito proustiano de memória involuntária é semelhante a um conteúdo de raiz inconsciente. Em outros termos, se a memória involuntária corresponde à memória na acepção psicanalítica, que por sua vez é considerada nesta acepção inconsciente, logo, a memória involuntária é inconsciente. Com efeito, é assim que a segunda materialização do inconsciente pode ser pensada. É com vistas à possibilidade de existência de um objeto material que remete os sujeitos ao seu passado inconsciente, que a materialização do inconsciente pode ser concebida (BENJAMIN, 2011, 108).

A memória, aqui, difere da mera lembrança que o sujeito pode tentar evocar por vontade própria. A memória da experiência deve então ser disparada por um objeto potencial. Um objeto que traga em si tal inconsciente/memória/experiência, materializados. Feliz daquele que, ao percorrer as ruas de Paris, depara-se com objeto de tal força que o remeta à sua experiência por excelência, ou à experiência em sentido estrito, como Benjamin denomina (Ibid., 106).

Contudo, mais uma vez nos encontramos diante daquele mesmo impasse. Se a memória da experiência é dependente de objeto que a acione, isto é, que a remeta, tal envio se encontra nos olhos daquele que visualiza determinado objeto. O objeto não traz em si elementos inconscientes, mas desperta elementos inconscientes. Nesse sentido, é assim que a materialização do inconsciente pode ser concebida.

Uma vez que sabemos que a memória involuntária é inconsciente, precisamos agora nos perguntar de quais mecanismos ela se utiliza para irromper. É sabido que o irromper do seu conteúdo se dá a partir do encontro com o objeto. De que maneira tal reenvio ao passado se desenvolve? Como se dá o acesso ao inconsciente a partir 
do encontro com o objeto? E uma vez que Walter Benjamin considera o inconsciente freudiano, convém utilizarmos outros mecanismos da psicanálise que também envolvam aquele mesmo inconsciente na tentativa de melhor explicar tal fenômeno. Nessa direção, supomos que tal processo pode ser vislumbrado de duas formas: pelas lembranças encobridoras e pelo processo de regressão nos sonhos.

\subsection{O conceito de lembrança encobridora}

É ao escrever sobre o curioso fato da amnésia que nos impede de recordarmos dos tempos de nossa infância, que Freud forja o conceito que denominou de lembrança encobridora. O psicanalista observa que os sujeitos em idade adulta pouco se lembram de sua infância e que o máximo que conseguem recordar dos eventos vividos, num fio de raciocínio encadeado, concentra-se dos 7 anos em diante. Em outros termos, os indivíduos em idade adulta parecem apenas conservar recordações do seu sétimo aniversário em diante, parecendo existir um vazio de experiências vivenciadas nos anos anteriores a tal período (FREUD, 2006d).

Podemos pensar, escreve Freud, que o conteúdo de tais recordações deve sua lembrança àquilo que foi mais marcante na vida do indivíduo. Isso nos leva a supor que tanto crianças quanto adultos procedem de maneira semelhante na conservação das lembranças que the causaram maior impressão (lbid.).

Porém, exemplos curiosos põem em questão a recordação apenas dos fatos que nos marcaram profundamente. $O$ que falar das recordações triviais, pergunta-nos Freud. O que dizer de recordações prescindíveis que são lembradas de maneira pormenorizada, com riqueza de cores e detalhes, e são coetâneas a outros acontecimentos que, segundo relatos de pessoas próximas à infância do indivíduo que tenta recordar, julgam tê-lo marcado profundamente? (FREUD, 1996b, 289). Esse aparente paradoxo é justamente o modo como se processa a lembrança encobridora, registra Freud. Na lembrança encobridora, "[...] os elementos essenciais de uma experiência são representados na memória pelos elementos não essenciais da mesma experiência" (Ibid., 291). Nesse passo, a fragmentação da memória aponta menos para o esquecimento propriamente dito do que para uma omissão, porque os elementos aparentemente triviais fazem parte da trama maior da memória que subjaz 
adormecida. Com efeito, é na noite do inconsciente que a parte essencial da memória adormece, e o trabalho de restauração de tal memória fica a encargo do tratamento analítico.

É com tal desenvolvimento em mente que dizemos que o objeto no qual o inconsciente se encontra materializado produz efeito semelhante ao conceito de lembrança encobridora. Assim, do mesmo modo que o sujeito, ao mordiscar a madeleine embebida em chá, é transportado de volta para o passado numa explosão de recordações, a análise pode suprir o indivíduo com satisfação similar, ao também proporcionar inúmeras lembranças de sua infância perdida.

Contudo, diferentemente do trabalho de análise, que necessita do par terapêutico para a reconstituição da memória, na materialização no objeto a lembrança irrompe de modo espontâneo. O despertar da memória não depende de um guia representado na pessoa do psicanalista que ajudará o analisando a recuperar as lembranças esquecidas. Não há o trabalho mitigado da análise, na qual cada lembrança será analisada e interpretada pelo psicanalista, em busca de quais lembranças se encontram sobrepostas àquela lembrança inicial.

\subsection{O processo de regressão dos sonhos}

Freud trata da regressão dos sonhos no segundo volume de sua Interpretação dos sonhos. Por tal regressão se entende o movimento de retorno à vivência sensorial que fora representada nos sonhos. Dito de outro modo, a regressão é a decomposição da tela onírica em sua matéria-prima. Assim, o caminho inverso é traçado da lembrança como imagem onírica para a multiplicidade de sensações que compõem inicialmente tal imagem. Como exemplo, se tenho como lembrança onírica a brincadeira com meu sobrinho em um campo de alfazemas, por meio da regressão posso reviver os elementos sensoriais dessa imagem como o cheiro das flores, o brilho ofuscante do sol, o carinhoso abraço do meu sobrinho. Dizemos que tal processo de regressão indica momento de "vigília" nos sonhos. Contudo, no estado de vigília tal movimento retrocedente não vai além das imagens mnêmicas, escreve Freud. Na vigília não nos é permitido sentir em absoluto a intensidade sensorial de um 
pensamento onírico. O máximo que podemos conseguir é a lembrança de tal pensamento.

Dizemos que esse processo de regressão nos sonhos pode ser vinculado à explosão sensorial que a madeleine desperta no personagem proustiano, uma vez que a sensação que irrompe de tal objeto o deixa prenhe não só das lembranças de sua infância, como vagas imagens, mas também cheio de sensações, ou seja, numa revivescência daquelas sensações iniciais.

Os dois mecanismos que podem ser pensados junto com a materialização do inconsciente a partir da madeleine proustiana apresentam diferenças consideráveis que necessitam de maior desenvolvimento. Sendo assim, uma vez que dizemos que tal materialização pode ser pensada a partir daquelas duas perspectivas psicanalíticas e não apenas uma, é preciso esclarecer da melhor maneira nossa hipótese.

Das duas perspectivas psicanalíticas escolhidas uma se dá como fruto da resolução analítica na prática clínica, enquanto a outra se dá pelo processo da atividade onírica. Dito de outro modo, enquanto a lembrança encobridora é descoberta a partir do trabalho de investigação analítica dirigida pelo psicanalista na situação clínica, o mecanismo dos sonhos chamado de regressão se dá no contexto particular do indivíduo que sonha.

No contexto proustiano, vimos que o encontro com a madeleine, além do remeter o indivíduo ao seu passado, também proporciona uma série de afetações. 0 gosto do chá misturado com os pedacinhos da madeleine produziu a explosão de sensações que tornaram atenuadas as vicissitudes da vida, ao mesmo tempo em que um crescente estado de alegria se instaurava.

Pode-se observar que tal momento não se trata de sonho em que um sujeito qualquer sonha comer um biscoito que fora servido por sua mãe. Nessa direção, o momento da degustação da madeleine se dá no campo da vigília, ou seja, na situação usual em que o sujeito meramente se alimenta.

Porém, apesar de o encontro com a madeleine se dar no contexto desperto, isto é, em vigília, isso não invalida nossa analogia com o mecanismo da regressão nos sonhos. Dizemos isso porque tanto o irromper das lembranças encobridoras na situação clínica quanto o movimento de decomposição das sensações em matériaprima nos sonhos que realiza a regressão apontam para um fio comum: o 
inconsciente. Assim, o fato de o contato com a madeleine produzir uma explosão de sensações e afetos reforça a analogia com o processo de regressão dos sonhos.

Do mesmo modo, dizemos que aquele encontro desperta a série de lembranças que pareciam se encontrar sobrepostas à lembrança do sabor que a mistura do chá com os farelos do biscoito proporcionou ao sujeito. Com efeito, é a equiparação benjaminiana da memória involuntária proustiana ao inconsciente freudiano que faz com que a busca por mecanismos inconscientes seja pertinente. Nesse sentido, não queremos forçar ao trazer junto ao texto benjaminiano conceitos que sequer foram mencionados. Contudo, num exercício de raciocínio queremos apenas nos perguntar se o uso desses mecanismos é possível diante da observância daquela equiparação. Se o inconsciente se faz presente no contexto da madeleine, de quais mecanismos se utiliza ao reenviar o indivíduo à sua infância perdida?

Nesse passo, o uso do inconsciente nos autoriza a buscar quais mecanismos a memória involuntária utiliza para irromper no sentido do acesso àquilo que Benjamin denominou de experiência em sentido estrito. Se tal busca é possível pode-se dizer, sem sombra de dúvida, que a experiência em sentido estrido é de raiz inconsciente. Mas não só por isso. O filósofo cita Freud, considerando o aparelho psíquico como um todo e não apenas a consciência ou a teoria do trauma ao desenvolver o conceito de experiência.

"Segundo Freud, a função de acumular 'traços permanentes como funcionamento da memória' em processos estimuladores está reservada a 'outros sistemas', que devem ser entendidos como diversos da consciência" (BENJAMIN, 2011, 108). Por tais sistemas diversos da consciência deve-se entender o préconsciente e o inconsciente. Nesse sentido, pode-se observar que, além da consideração do inconsciente, a atenção de Walter Benjamin se volta para o aparelho psíquico como um todo; para a responsabilidade da consciência na recepção e proteção contra os estímulos; e, do mesmo modo, para o acesso que o pré-consciente possibilita aos conteúdos inconscientes irromperem na consciência. Assim, uma leitura de Charles Baudelaire: um lírico no auge do capitalismo a partir dos conceitos psicanalíticos manifestos se daria da seguinte forma: a onipresença das situações de choque na Modernidade bloqueia o acesso à memória, logo, ao inconsciente. Nessa perspectiva, o sistema percepção-consciência tem por função proteger o aparelho 
psíquico do desconforto dessas excitações. Funcionando como escudo protetor, tal barreira somente é rompida mediante forte excitação, ou seja, uma excitação potencialmente traumática.

Contudo, supomos que o real interesse de Benjamin pode ser identificado na relação entre o sistema percepção-consciência e a memória, uma vez que tal relação aponta para o conceito de experiência. Tal dinâmica do aparelho psíquico permite vislumbrar a possibilidade de acesso aos conteúdos mais profundos de nossa psique. Conteúdos inconscientes que correspondem à experiência propriamente dita, que correspondem a elementos da história que precisam ser rememorados.

Ao servir de ponte entre os estímulos recebidos pelo mundo externo que adentram a psique dos indivíduos por meio da consciência, o pré-consciente, ou inconsciente descritivo, ao mesmo tempo se mantém em contato com a camada mais profunda do inconsciente, denominada de inconsciente dinâmico. O prejuízo na memória que o excesso de excitações ocasiona ao inundar o aparelho psíquico dos citadinos de Paris do século XIX, deixando-os ricos em vivências e pobres em experiência, dá-se em camadas, partindo de estímulos inicialmente banais do mundo externo até sua chegada às lembranças mais importantes, que povoam tal inconsciente descritivo independente da força da excitação, ou seja, um trauma, até desembocarem no inconsciente dinâmico. Com efeito, uma vez que é neste último que a experiência, em sentido estrito, faz sua morada, é assim que a atrofia da memória se processa.

\section{Uma recuperação da experiência}

Vimos, anteriormente, a maneira como se processa a atrofia da experiência. Vimos também que tal prejuízo se dá em camadas, partindo de estímulos do mundo externo até chegar ao inconsciente, lugar onde habita a experiência.

A tarefa aqui proposta é pensar numa possibilidade de recuperação de tal experiência bloqueada. Como pensar num panorama diferente para a experiência? No contexto em que esta ainda possa brotar em terreno fértil. Será que em cidades menores, ou em habitações no campo, essa onipresença das situações de choque é menor? Será que esses moradores têm acesso à experiência em sentido estrito, uma 
vez que não sofrem a influência dos inúmeros estímulos? Ou seja, em cidades menores, sem acesso a novas técnicas, com ruas quase desertas, a experiência pode ainda florescer? Se não for o caso, como pensar na possibilidade da experiência?

De uma coisa sabemos, se os dados da experiência existem no inconsciente, é por meio dele que é permitido o acesso. Porém, para Kehl, a passagem do texto benjaminiano que aponta para a "[...] conjunção, na memória, de certos conteúdos do passado individual com outros do passado coletivo" (BENJAMIN, 2011, 107) não nos leva a deduzir "que o registro da transmissão da experiência seja o do inconsciente recalcado, e sim o de um estado de inconsciência tributário do repouso do sistema percepção consciência" (KEHL, 2014, 169-170). Contudo, tal observação não impossibilita pensarmos na possibilidade de recuperação da experiência, uma vez que a transmissão ainda continua via inconsciente. Assim, reforçamos ainda mais tal possibilidade, tendo em vista a utilização, por parte de Walter Benjamin, das principais teorias psicanalíticas. Uma vez que, para a psicanálise, conteúdos inconscientes podem irromper na consciência, dizemos, de semelhante modo, que a experiência como elemento inconsciente também pode irromper na consciência dos sujeitos na grande cidade.

Além do que, parece que a possibilidade atual de um objeto que materialize o inconsciente, ou que tenha em si o inconsciente materializado, encontra-se fadada ao fracasso, uma vez que aquela onipresença das situações de choque corrobora para seu fim. Para Proust, o encontro com um objeto de tal tipo, que tivesse materializado o inconsciente, depende da contingência do acaso. De semelhante modo, para Benjamin, em virtude do treinamento do sistema sensorial, além da atrofia, tal encontro parece não ser mais possível. Portanto, supomos que a teoria dos atos falhos surge então como uma poderosa aliada em vista da provável recuperação da experiência.

Encontrar-se-á a teoria freudiana dos atos falhos desenvolvida em Sobre a psicopatologia da vida cotidiana. Nesse texto, Freud observa que o desejo inconsciente, antes localizado no cerne dos processos oníricos, é também ampliado à vida desperta dos indivíduos a partir dos atos falhos. Visto como um engano, um ato falho se caracteriza por equívocos, esquecimentos e ações desastrosas ocorridos no dia a dia, que passariam despercebidas à luz de observação desatenta ao 
determinismo psíquico inconsciente. Assim, o ato falho, que antes poderia parecer trivial ou sem importância, passa a partir de então a ser considerado, sob a ótica da psicanálise, um elemento de preciosa consideração. Por exemplo, antes de atribuímos o esquecimento do nome de um colega de trabalho, que encontramos no mercado da esquina, ao intenso movimento de pessoas e à dispersão de nossa atenção pelas ofertas do dia, Freud aponta para a influência de pensamentos inconscientes como o verdadeiro motivo para esse lapso.

Determinados por um fio causal de raiz inconsciente, os atos falhos marcam um momento de cesura na atividade vigilante do consciente. Nessa oportunidade, os pensamentos inconscientes podem irromper, mas não sem modificação. Estimulado pelo mundo externo, o homem, no seu cotidiano movido pelos pensamentos inconscientes, termina por se projetar nas coisas do mundo. E como nos sonhos, a passagem de pensamentos inconscientes por meio daquela cesura também sofre a influência da repressão e do desejo. Quando um pensamento inconsciente tenta irromper na consciência, a repressão ou a cesura acarretam a distorção na expressão de tal desejo. Nesse passo, enquanto nos sonhos aqueles mecanismos operam a distorção que pode ser traduzida por uma fusão de imagens, em fluxo caótico e absurdo, nos atos falhos tais processos operam de maneira diferente. Portanto, a influência daqueles processos no cotidiano das pessoas se dá nos lapsos da fala, escrita e leitura (FREUD, 1996a).

Além dos atos falhos se dividirem nos lapsos de fala, escrita e leitura, Freud ainda aponta os equívocos na ação e o esquecimento de nomes próprios como também pertencentes a essa categoria. É certo que não tenho a intenção de aqui desenvolver cada um desses fenômenos, mas sim apresentar como se processa a influência do inconsciente em nossa vida ordinária, uma vez que dizemos que, se seguirmos por esse caminho, uma possível recuperação da experiência pode ser pensada a partir da teoria freudiana dos atos falhos. Mas por que tal possibilidade se encontra vinculada aos atos falhos? Por que não utilizar os outros mecanismos da materialização, tais como as lembranças encobridoras ou o movimento de regressão dos sonhos?

Utilizamos os atos falhos simplesmente por não sabermos da existência de um objeto que traga em si a experiência materializada, além de estarmos sempre 
dependentes daquela contingência. Contudo, sob a perspectiva da teoria dos atos falhos, a materialização passa a ser uma realidade possível. Vimos, com Freud, que os atos falhos nos acompanham no dia a dia. Podemos, então, todo dia nos projetar nas coisas do mundo materializando nosso inconsciente.

Contudo, mais uma vez, nos encontramos diante daquele mesmo problema da individualidade do inconsciente. Se o mundo externo somente desperta conteúdo do inconsciente particular de cada sujeito, como conceber tal teoria dos atos falhos como uma provável recuperação da experiência?

Na leitura de Benjamin, vimos que a experiência é formada por conteúdo tanto do passado individual quanto do passado coletivo unidos na memória dos sujeitos. Com efeito, não é somente de elementos do passado individual - logo, do inconsciente de cada um - que a experiência se constitui.

Contudo, se considerar o momento de censura que implica os atos falhos podese vislumbrar um acesso àquele conteúdo da experiência. Nesse passo, aquilo que recentemente me afeta se liga de algum modo ao conteúdo de ordem mais profunda, ao conteúdo inconsciente da espécie. Do mesmo modo, dizemos que aquelas mesmas sensações que outrora se avolumavam no sistema sensorial dos sujeitos e prejudicavam suas memórias, agora podem ser utilizadas para a recuperação dessa mesma memória. A recepção das sensações misturadas à projeção do inconsciente funcionaria ao modo de um objeto como a madeleine. Porém, um objeto mais fácil de encontrar.

Tal possibilidade de acesso se torna mais clara se pensarmos no modo como se processa a dinâmica dos sonhos, uma vez que tal possibilidade se aproxima da ampliação do inconsciente para a vida cotidiana. Mezan observa, em Freud e a trama dos conceitos, que a interpretação freudiana dos atos falhos é igual à análise dos sonhos, tendo as duas o mesmo objetivo: a demonstração do determinismo dos atos da vida psíquica, mesmo aqueles considerados mais banais (MEZAN, 2008, 100).

Para Freud, o sonho é realização de um desejo, logo, seu conteúdo é inconsciente. Vimos que o inconsciente se apresenta ao modo de uma gradação, isto é, em níveis. Assim, o inconsciente dinâmico se estabelece no nível mais profundo que o inconsciente descritivo. Porém, na dinâmica dos sonhos podemos dizer que tais níveis apresentam verticalidade, que permite melhor passagem e interpenetração de 
seus conteúdos. Dito de outro modo, os conteúdos pertencentes ao inconsciente dinâmico conseguem penetrar de maneira mais fácil o inconsciente descritivo e chegar à consciência. Contudo, a mesma facilidade não é encontrada no estado de vigília, no estado que é palco dos atos falhos. No estado de vigília, esses inconscientes não se comunicam entre si de maneira direta. Assim, tal comunicação pode se dar por meio da lembrança encobridora ou por meio dos atos falhos.

A comunicação por meio da lembrança encobridora se dá entre uma lembrança que aponta no inconsciente descritivo, mas cuja raiz subjaz no inconsciente dinâmico. A ponta dessa raiz aparece como duplo conteúdo, em que imagens coadunam advindas de diferentes níveis. Nesse sentido, os estímulos externos que se assomam em nossa consciência podem se vincular, do mesmo modo que a ponta daquela raiz, permitindo assim a comunicação entre ambos os inconscientes. Vimos também que a lembrança encobridora é justamente uma lembrança justaposta, na qual o conteúdo antigo se deslocou, ligando-se a outro mais recente. Contudo, também é de nosso conhecimento que é por meio do trabalho analítico que a lembrança encobridora pode vir à tona e é justamente tal característica que impossibilita seu uso para o acesso à experiência. Em outros termos, como no caso da madeleine, podemos também supor, por exemplo, um sujeito de 40 anos, que o ato de tomar café remete a uma vaga lembrança trivial de sua infância. Porém, quando questionado por seu analista por detalhes do conteúdo, tal indivíduo descobre que se trata de uma lembrança encobridora, irrompendo a partir de então o contexto maior do qual essa lembrança oferecia apenas uma minúscula parte.

No caso do acesso que permite os atos falhos, dizemos que tal impossibilidade de irromper de maneira espontânea não se encontra vedada. A partir dos atos falhos, um objeto que produz o efeito como a madeleine pode de fato ser pensado livre da contingência do acaso. Nessa esteira, se transpormos o sujeito do desjejum matinal para a grande cidade de Baudelaire um lírico no auge do capitalismo, dizemos que a mesma dinâmica de justaposição de conteúdo pode ser encontrada. Assim o citadino de Paris do século XIX, no seu caminhar cotidiano, encontra-se submetido a toda sorte de estímulos. Com efeito, num primeiro momento, estímulos de toda ordem afetam sua consciência. Em outras palavras, o homem na grande cidade tem sua consciência invadida pelos mais diversos choques, como estímulos táteis, auditivos, visuais, 
olfativos. A consciência como responsável em aparar essa gama de estímulos opera como escudo protetor.

Contudo, um desses estímulos afeta o indivíduo, despertando a projeção de seu inconsciente. Tal estímulo recebido na vigília e aparado na consciência percorre o inconsciente descritivo até chegar ao inconsciente dinâmico, o lugar residência da experiência. Dito de outro modo, uma vez que esses estímulos se comunicam por entre as camadas inconscientes, dizemos que os estímulos visitantes perpassam por entre as camadas do aparelho psíquico, comunicando-se com aqueles conteúdos sedimentados no inconsciente. E é desse modo que uma possível materialização do inconsciente mais próxima à madeleine proustiana pode ser vislumbrada. É desse modo que o acesso à experiência é possível.

Como exemplo, o homem que comete um lapso de leitura pode, por engano, ler em um letreiro que informa "barbearia" a palavra "banheiro". Pode-se objetar que, por vezes, incorremos em erros similares a esse, por conta de falta de atenção, olhar distraído ou estado de fadiga que nos proporciona os mais variados enganos. $E$ que nunca um equívoco como este nos levaria ao conteúdo da experiência em sentido estrito. Contudo, Freud também tinha tais possibilidades de distração em mente e, mesmo assim, não deixou de considerar a influência dos atos falhos em nossa vida cotidiana, mantendo a censura no mundo de vigília aberta.

Portanto, movido pela ordem do desejo o sujeito tem sua percepção influenciada, uma vez que conteúdos inconscientes motivam seu engano. É como se, guardadas as devidas proporções, os homens em seu estado de vigília se aproximassem da dinâmica parecida com a dos sonhos, em que seu conteúdo onírico é invadido pelos desejos do inconsciente. Com efeito, o lapso aparentemente se configura no instante de sonho na vigília do indivíduo, ganhando força a possibilidade da materialização do inconsciente, além de apontar quão tênue é a linha que separa o mundo desperto do mundo de vigília.

Resumamos os principais pontos a que a investigação sobre a possibilidade da materialização do inconsciente nos levou. Vimos que, na grande cidade, na Paris do século XIX, a multidão e o surgimento de novas técnicas sobrecarregam o citadino moderno de novas sensações, imprimindo nos sujeitos um treinamento do aparelho sensorial que resultou em prejuízo à memória. Essa onipresença de situações de 
choque resultou em redução da experiência. Contudo, tal quadro de atrofia desta última vê a possibilidade de um prognóstico mais animador, em vista de Walter Benjamin apontar o local onde reside a experiência, bem como seu conteúdo. Entretanto, vimos que tal possibilidade não se limita apenas ao conhecimento daquele conteúdo e local da experiência. Nesse sentido, tal possibilidade se concentra no uso de algumas das principais teorias da psicanálise, o que nos levou a dizer que o processo de atrofia da experiência, a sua composição e o local onde habita são absorvidos numa perspectiva freudiana e expelidos ao modo benjaminiano. Assim, vimos que a experiência é formada por conteúdos da vida individual e coletiva dos sujeitos, e o inconsciente é onde ela faz residência.

Walter Benjamin toma de empréstimo a psicodinâmica do aparelho psíquico, encontrada na teoria psicanalítica do trauma, e aplica-a no desenvolvimento de sua tese sobre a atrofia da experiência. Vimos também que esta última é formada por dois conteúdos: pelos dados isolados que correspondem a elementos do passado individual dos indivíduos e, em sua maior parte, pelos conteúdos formados por elementos do passado coletivo da espécie.

Essa investigação nos trouxe a possibilidade de vislumbramos ao menos duas materializações no texto benjaminiano. A primeira pensada a partir das passagens é representada pelas mercadorias que são cultuadas como objetos de desejo e se traduzem pela expressão do inconsciente. Já a segunda é concebida a partir do conceito proustiano de memória involuntária, tendo a madeleine como expressão de tal materialização. Vimos que é a partir da existência de objeto como a madeleine que a experiência pode mais uma vez vir à tona, que a experiência em sentido estrito pode irromper. Além de tal possibilidade de retorno da experiência, foi possível observar que a memória involuntária se traduz pelo conceito de inconsciente da psicanálise. Tal observação nos levou a perguntar quais mecanismos, vistos da perspectiva também psicanalítica, melhor explicariam o fenômeno da materialização. Desse modo, supomos que tal processo pode ser vislumbrado de duas formas, a saber, pelas lembranças encobridoras e pelo processo de regressão nos sonhos. É por meio desses dois mecanismos que os conteúdos inconscientes, logo, a experiência, podem irromper na consciência dos sujeitos na grande cidade. 
Contudo, vimos que a possibilidade de materialização pode fracassar, uma vez que para Proust o encontro com objeto de tal tipo, que tivesse materializado o inconsciente, depende da contingência do acaso. Do mesmo modo, para Benjamin, em virtude do treinamento do sistema sensorial, ademais a atrofia, tal encontro parece não ser mais possível. Portanto, supomos que a teoria dos atos falhos surge então como uma poderosa aliada em vista da provável recuperação da experiência, uma vez que esta se apresenta como possibilidade real.

\section{REFERÊNCIAS}

BENJAMIN, W. Passagens. Belo Horizonte: Ed. UFMG; São Paulo: Imprensa Oficial do Estado de São Paulo, 2007.

. Sobre alguns temas em Baudelaire. In_ : Charles Baudelaire: um lírico no auge do capitalismo. São Paulo: Brasiliense, 2011. (Obras escolhidas, v. III).

FREUD, S. A interpretação dos sonhos. Trad. Walderedo Ismael de Oliveira. In__: Edição standard brasileira das obras psicológicas completas de Sigmund Freud. Rio de Janeiro: Imago, 2006b. v. 4 e v. 5.

. Além do princípio de prazer. Trad. Christiano Monteiro Oiticica. In_ :

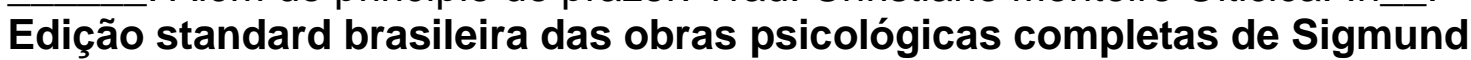
Freud. Rio de Janeiro: Imago, 2006a. v. 18.

. Conferências introdutórias sobre psicanálise. Tradução de Jayme Salomão. In_ _ Edição standard brasileira das obras psicológicas completas de Sigmund Freud. Rio de Janeiro: Imago, 2006e. v. 15 e 16.

. Lembranças encobridoras. Tradução de Jayme Salomão. In_ _ Edição standard brasileira das obras psicológicas completas de Sigmund Freud. Rio de Janeiro: Imago 2006d. v. 3.

Sobre a psicopatologia da vida cotidiana. Tradução de Jayme Salomão. In__: Edição standard brasileira das obras psicológicas completas de Sigmund Freud. Rio de Janeiro: Imago, 2006c. v. 6.

GARCIA-ROZA, L. A. Freud e o inconsciente. Rio de Janeiro: Jorge Zahar, 2005.

KEHL, M. R. O tempo e o cão: a atualidade das depressões. São Paulo: Boitempo, 2014.

MEZAN, R. Freud: a trama dos conceitos. São Paulo: Perspectiva, 2008. 
PROUST, M. Em busca do tempo perdido: no caminho de Swann. Trad. Fernando Py. Rio de Janeiro: Nova fronteira, 2014.

ROUANET, S. P. Édipo e o anjo: itinerários freudianos em Walter Benjamin. Rio de Janeiro: Tempo Brasileiro, 1981. 